\title{
NHC-Assisted One-Pot Domino Oxidation of Aldehydes into Carboxylic Acids using Sodium Hydride under Oxygen Atmosphere
}

\author{
Sun Min Kim, Young Sug Kim, and Jung Woon Yang* \\ Department of Energy Science, Sungkyunkwan University, Suwon 440-746, Korea. *E-mail: jwyang@skku.edu \\ Received June 2, 2011, Accepted June 21, 2011
}

Key Words : Domino oxidation, $N$-Heterocyclic carbene, Carboxylic acid, Sodium hydride

Domino reactions are powerful tools in synthetic chemistry for the formation of target molecules in a single flask without the isolation of intermediates, and hence the number of reaction steps is reduced and waste may be minimized. ${ }^{1}$ As part of a wider research program aimed at exploring new domino reactions, we became interested in developing a new strategy for the oxidation of aldehydes to the corresponding carboxylic acids. ${ }^{2}$ Surprisingly, despite impressive advances in the area of oxidation, domino reactions have not been applied to the oxidation of aldehydes to carboxylic acids. ${ }^{3}$ Very recently, we began to explore the utility of sodium hydride-molecular oxygen $\left(\mathrm{NaH}-\mathrm{O}_{2}\right)$ system and successfully applied to the oxidation of benzoins to benzils, ${ }^{4}$ and the oxidative cleavage of benzoins to benzoic acids. ${ }^{5}$ Based on these results, we envisioned that the combination of the selfbenzoin condensation of aldehyde and the oxidative cleavage of benzoin using $\mathrm{NaH}-\mathrm{O}_{2}$ could provide a conceptually new domino oxidation reaction. Herein we report our preliminary results on NHC-assisted one-pot domino oxidation.

To identify the feasibility of our approach, we first carried out domino benzoin condensation/ $\mathrm{NaH}-\mathrm{O}_{2}$ oxidation with $p$ chlorobenzaldehyde 1a. Thus, self-benzoin condensation reaction of $\mathbf{1 a}$ in the presence of $50 \mathrm{~mol} \% \mathrm{~N}$-heterocyclic carbene (NHC) precatalyst $3 \mathbf{c}$ with $\mathrm{K}_{2} \mathrm{CO}_{3}$ as a base in $\mathrm{CH}_{2} \mathrm{Cl}_{2}$ for $24 \mathrm{~h}$ yielded the intermediate $\mathbf{I}^{6}{ }^{6}$ The successive addition of 1 equivalent of $\mathrm{NaH}$ in a mixed solvent of THF and $\mathrm{CH}_{2} \mathrm{Cl}_{2}$ under oxygen atmosphere, provided the desired $p$-chlorobenzoic acid 2a in a 77\% yield after $10 \mathrm{~min}$ (Scheme 1).

We next attempted to develop one-pot domino reactions by employing $\mathrm{NHC}$ precatalyst $/ \mathrm{NaH}-\mathrm{O}_{2}$ together. Our studies began with an initial examination of the catalytic activities of several $\mathrm{NHCs}^{7}$ 3a-e for the domino oxidation of 1a. The results are summarized in Table 1 . The NHC precatalysts 3a,

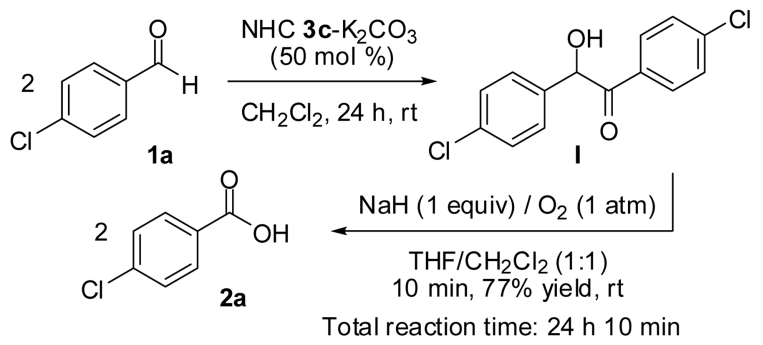

Scheme 1. Sequencing reaction for oxidation of aldehyde to carboxylic acid. 3b derived from imidazolium salt produced the desired product $2 \mathrm{a}$ in $58 \%$ and $78 \%$ yields after $30 \mathrm{~min}$ and $2 \mathrm{~h}$, respectively (Table 1, entries 1-2). Among the imidazolium salts 3a-c, 3c is capable of catalyzing the reaction in undegassed dry THF to give $\mathbf{2 a}$ in a $72 \%$ yield after only 10 min under $\mathrm{NaH}-\mathrm{O}_{2}$ system (Table 1 , entry 3 ). Noteworthy is that the current one-pot, domino oxidation methodology is superior to the sequencing reaction in terms of reaction rate. Even if the turnover frequency in the benzoin formation step is much lower than that in the oxidative cleavage step, presumably, 1a was quickly consumed in relatively large quantities by $\mathrm{NaH} / \mathrm{O}_{2}$, thereby producing the desired product 2a within $10 \mathrm{~min}$. In contrast, the reaction was sluggish and gave lower yield $(32 \%)$ without oxygen atmosphere (Table 1 , entry 4), which was attributed to the remaining selfbenzoin product $\mathbf{I}$. We also investigated the effects of solvent and $\mathrm{NaH}$ loading. Replacing the solvent THF with EtOAc or toluene led to lower chemical yields (Table 1, entries 7-8). With the use of precatalyst 3c (10 mol \%) and $\mathrm{NaH}(0.6$ equiv) under oxygen atmosphere, the desired product was formed in poor yield (32\%) due to the major portion of unreacted aldehyde 1a, the formation of the 4,4'-chloro-

Table 1. Optimization of the reaction conditions ${ }^{a}$

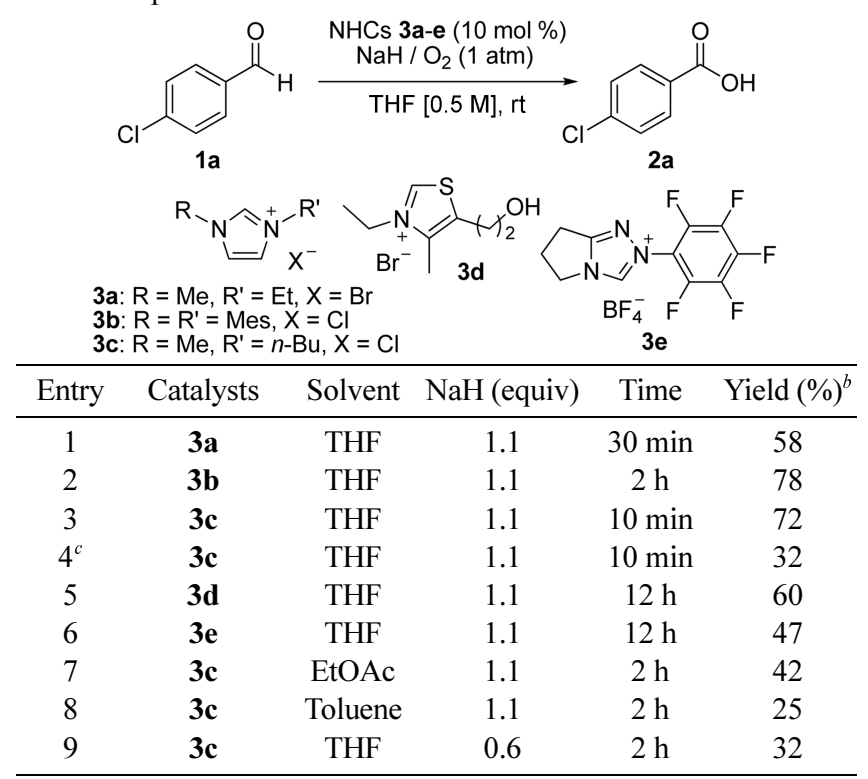

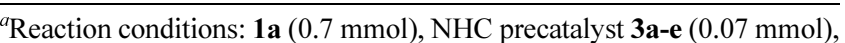
$\mathrm{NaH}\left(60 \%\right.$ dispersion in mineral oil, 0.6 or 1.1 equiv), $\mathrm{O}_{2}$ (1 atm), rt. ${ }^{b}$ Isolated yield. ${ }^{c}$ Without oxygen atmosphere. 
benzoin I, and the trace amounts of remaining 4,4'-chlorobenzil, all of which were isolable and confirmed via ${ }^{1} \mathrm{H}$ and ${ }^{13} \mathrm{C}$ NMR spectroscopies (Table 1, entry 9).

The above results indicated that this protocol involved 4,4'-chlorobenzoin I as a key intermediate for the subsequent oxidation mediated by $\mathrm{NaH}-\mathrm{O}_{2}$ system, which is solid evidence that aldehyde 1a is not directly oxidized to carboxylic acid 2a under this reaction condition. In a related study, Lewis reported a single example of oxidation of $p$-nitrobenzaldehyde using a $\mathrm{NaH}-\mathrm{O}_{2}$ system, and proposed that the reaction occurred by Cannizzaro reaction, thereby producing $p$-nitrobenzoic acid with accomplishing of $p$-nitrobenzyl alcohol. ${ }^{8}$ In contrast, under our newly designed system, the corresponding benzyl alcohols were not observed in any cases, indicating that the oxidation was not related to the Cannizzaro reaction pathway. To demonstrate the differentiation between our current protocol and Lewis' method, we carried out the reactions of 4-methylbenzaldehyde $\mathbf{1 h}$ and $p$-chlorobenzaldehyde 1a with $\mathrm{NaH}$ either in the presence or absence of the NHC precatalyst $3 \mathbf{c}$ under oxygen atmosphere (Table 2). Quite surprisingly, the trace amount of the desired product $\mathbf{2 h}$ ( $<5 \%$ yield) was observed (Table 2 , entry 1$)$ during the reaction of $\mathbf{1 h}$ bearing an electron-donating group in the absence of the NHC precatalyst 3c under $\mathrm{NaH}-\mathrm{O}_{2}$ system, whereas with the use of precatalyst 3c under $\mathrm{NaH}-\mathrm{O}_{2}$ system resulted in an large amount of the product $2 \mathbf{h}(82 \%$ yield; Table 2, entry 2). A similar pattern was observed when 1a

Table 2. Comparison of concept for the oxidation of aldehydes

\begin{tabular}{|c|c|c|c|c|}
\hline Entry & $\mathrm{Ar}$ & Conditions & Time & Yield $(\%)^{a}$ \\
\hline 1 & $4-\mathrm{Me}-\mathrm{C}_{6} \mathrm{H}_{4}$ & without precatalyst 3c & $8 \mathrm{~h}$ & $<5$ \\
\hline 2 & $4-\mathrm{Me}-\mathrm{C}_{6} \mathrm{H}_{4}$ & with precatalyst $\mathbf{3 c}$ & $8 \mathrm{~h}$ & 82 \\
\hline 3 & $4-\mathrm{Cl}-\mathrm{C}_{6} \mathrm{H}_{4}$ & without precatalyst $\mathbf{3 c}$ & $10 \min$ & 22 \\
\hline 4 & $4-\mathrm{Cl}-\mathrm{C}_{6} \mathrm{H}_{4}$ & with precatalyst $\mathbf{3 c}$ & $10 \mathrm{~min}$ & 72 \\
\hline
\end{tabular}

${ }^{a}$ Isolated yield.

Table 3. Substrate scope for the domino oxidation of aldehydes ${ }^{a}$ $\mathrm{NHC} 3 \mathrm{c}(10 \mathrm{~mol} \%)$

\begin{tabular}{|c|c|c|c|}
\hline Entry & $\mathrm{Ar}$ & Time & Yield $(\%)^{b}$ \\
\hline 1 & $4-\mathrm{Cl}-\mathrm{C}_{6} \mathrm{H}_{4}(\mathbf{a})$ & $10 \mathrm{~min}$ & 72 \\
\hline 2 & $3-\mathrm{Cl}-\mathrm{C}_{6} \mathrm{H}_{4}(\mathbf{b})$ & $10 \mathrm{~min}$ & 83 \\
\hline 3 & $4-\mathrm{CF}_{3}-\mathrm{C}_{6} \mathrm{H}_{4}(\mathbf{c})$ & $20 \min$ & 77 \\
\hline 4 & $4-\mathrm{NC}-\mathrm{C}_{6} \mathrm{H}_{4}(\mathbf{d})$ & $10 \mathrm{~min}$ & 90 \\
\hline 5 & $4-\mathrm{NO}_{2}-\mathrm{C}_{6} \mathrm{H}_{4}(\mathbf{e})$ & $10 \min (8 h)^{c}$ & $51(90)^{c}$ \\
\hline 6 & $\mathrm{Ph}(\mathbf{f})$ & $2 \mathrm{~h}$ & 72 \\
\hline 7 & 2-Naphthyl (g) & $8 \mathrm{~h}$ & 83 \\
\hline 8 & $4-\mathrm{Me}-\mathrm{C}_{6} \mathrm{H}_{4}(\mathbf{h})$ & $8 \mathrm{~h}$ & 82 \\
\hline 9 & $3-\mathrm{Me}-\mathrm{C}_{6} \mathrm{H}_{4}(\mathbf{i})$ & $8 \mathrm{~h}$ & 85 \\
\hline 10 & $4-\mathrm{MeO}-\mathrm{C}_{6} \mathrm{H}_{4}(\mathbf{j})$ & $8 \mathrm{~h}$ & 33 \\
\hline
\end{tabular}

${ }^{a}$ Reaction conditions: $1(0.7 \mathrm{mmol})$, NHC precatalyst $\mathbf{3 c}(0.07 \mathrm{mmol})$, $\mathrm{NaH}\left(60 \%\right.$ dispersion in mineral oil, 1.1 equiv), $\mathrm{O}_{2}(1 \mathrm{~atm})$, THF $[0.5$ $\mathrm{M}]$, rt. ${ }^{b}$ Isolated yield. ${ }^{c}$ Using NHC precatalyst $\mathbf{3 b}$. possessing an electron-withdrawing group was employed (Table 2, entries 3-4). It turned out that the reaction was significantly accelerated by the addition of NHC precatalyst 3c.

To explore the scope of substrate of our domino oxidation, various aldehydes were examined (Table 3 ). In general, the aromatic aldehydes 1a-d, which possesses electron withdrawing substituents, resulted in higher performance compared to those of electron donating substituents, and the reactions were completed within $20 \mathrm{~min}$ and produced the desired products in high yields $(72-90 \%)$.

In summary, we achieved one-pot, domino oxidations of aldehydes to their corresponding carboxylic acids using a combination of $\mathrm{NHC}$ catalyst and a $\mathrm{NaH}-\mathrm{O}_{2}$ system. Moreover, the dramatic acceleration effect was observed upon addition of NHC catalyst.

Acknowledgment. This work was supported by the NRF WCU program (R31-2008-10029) and NRF grant (No. 2010-0023127).

\section{References}

1. For general reviews on domino reactions, see: (a) Tietze, L. F.; Beifuss, U. Angew. Chem. Int. Ed. 1993, 32, 131. (b) Tietze, L. F. Chem. Rev. 1996, 96, 115. (c) Tietze, L. F.; Brasche, G.; Gericke, K. M. Domino Reactions in Organic Synthesis; Wiely-VCH: Weinheim, 2006.

2. For general reviews on the oxidation of aldehydes to carboxylic acids, see: (a) Hudlicky, M. Oxidations in Organic Chemistry, ACS Monograph Series 186; American Chemical Society: Washington, D.C., 1990; 174. (b) Hollingworth, G. J. In Comprehensive Organic Functional Group Transformations, Vol. 5; Katritzky, A. R., Meth-Cohn, O., Rees, C. W., Pattenden, G., Eds.; Elsevier: Oxford, 1995; 23. (c) Larock, R. C. Comprehensive Organic Transformations: A Guide to Functional Group Preparations, 2nd ed.; Wiley-VCH: New York, 1999; 1653.

3. The alternative direct methods for the oxidation of aldehydes to carboxylic acids catalyzed by $\mathrm{NHC}$ as organocatalysts. Using $\mathrm{CO}_{2}$ see: (a) Gu, L.; Zhang, Y. J. Am. Chem. Soc. 2009, 132, 914. (b) Nair, V.; Varghese, V.; Paul, R. R.; Jose, A.; Sinu, C. R.; Menon, R. S. Org. Lett. 2010, 12, 2653. Using $\mathrm{H}_{2} \mathrm{O}$, see: (c) Yoshida, M.; Katagiri, Y.; Zhu, W.-B.; Shishido, K. Org. Biomol. Chem. 2009, 7, 4062. (d) Vora, H. U.; Rovis, T. J. Am. Chem. Soc. 2010, 132, 2860. Using air, see: (e) Park, J. H.; Bhilare, S. V.; Youn, S. W. Org. Lett. 2011, 13, 2228. (f) Chiang, P.-C.; Bode, J. W. Org. Lett. 2011, 13, 2422.

4. Joo, C.; Kang, S.; Kim, S. M.; Han, H.; Yang, J. W. Tetrahedron Lett. 2010, 51, 6006.

5. Kang, S.; Joo, C.; Kim, S. M.; Han, H.; Yang, J. W. Tetrahedron Lett. 2011, 52, 502.

6. Xu, L.-W.; Gao, Y.; Yin, J.-J.; Li, L.; Xia, C.-G. Tetrahedron Lett. 2005, 46, 5317.

7. For general reviews on NHC catalysts, see: (a) Enders, D.; Balensiefer, T. Acc. Chem. Res. 2004, 37, 534. (b) Christmann, M. Angew. Chem. Int. Ed. 2005, 44, 2632. (c) Zeitler, K. Angew. Chem. Int. Ed. 2005, 44, 7506. (d) Enders, D.; Balensiefer, T.; Niemeier, O.; Christmann, M.; In Enantioselective Organocatalysis: Reactions and Experimental Procedures; Dalko, P. I., Ed.; WielyVCH: Weinheim, Germany, 2007; 331. (e) Marion, N.; Díez-González, S.; Nolan, S. P. Angew. Chem. Int. Ed. 2007, 46, 2988. (f) Enders, D.; Niemeier, O.; Henseler, A. Chem. Rev. 2007, 107, 5606. (g) Nair, V.; Vellalath, S.; Babu, B. P. Chem. Soc. Rev. 2008, 37, 2691. 8. Lewis, G. E. J. Org. Chem. 1965, 30, 2433. 